\title{
Design of a continuous-flow reactor for in situ x-ray absorption spectroscopy of solids in supercritical fluids
}

\author{
M. Dreher, ${ }^{\text {a) }}$ E. De Boni, M. Nachtegaal, J. Wambach, and F. Vogel \\ Paul Scherrer Institut, 5232 Villigen PSI, Switzerland
}

(Received 13 February 2012; accepted 5 May 2012; published online 22 May 2012)

\begin{abstract}
This paper presents the design and performance of a novel high-temperature and high-pressure continuous-flow reactor, which allows for x-ray absorption spectroscopy or diffraction in supercritical water and other fluids under high pressure and temperature. The in situ cell consists of a tube of sintered, polycrystalline aluminum nitride, which is tolerant to corrosive chemical media, and was designed to be stable at temperatures up to $500^{\circ} \mathrm{C}$ and pressures up to $30 \mathrm{MPa}$. The performance of the reactor is demonstrated by the measurement of extended x-ray absorption fine structure spectra of a carbon-supported ruthenium catalyst during the continuous hydrothermal gasification of ethanol in supercritical water at $400{ }^{\circ} \mathrm{C}$ and $24 \mathrm{MPa}$. (C) 2012 American Institute of Physics. [http://dx.doi.org/10.1063/1.4719921]
\end{abstract}

\section{INTRODUCTION}

Supercritical fluids are of growing importance as reaction media in various fields of science and technology, including geochemistry, catalysis, surface chemistry, and pharmaceutical chemistry. Prime examples are the crystal growth of minerals in supercritical water $(\mathrm{SCW}),{ }^{1-3}$ the hydrothermal conversion of biomass to produce "green fuels" ${ }^{"-6}$ or the synthesis of fine chemicals and pharmaceuticals in supercritical fluids. ${ }^{7-11}$ As the chemistry involved can be fundamentally different compared to reactions under more conventional conditions (liquid, subcritical solvents, or gases), it is indispensable to investigate these processes under in situ reaction conditions.

$\mathrm{X}$-ray absorption spectroscopy (XAS) is a potent technique for obtaining local geometric (up to $6 \AA$ ) and electronic structural information about the x-ray absorbing atoms. ${ }^{12} \mathrm{On}$ the other hand, $\mathrm{x}$-ray diffraction (XRD) provides information about crystalline phases (long range order) and lattice parameters of solid samples. ${ }^{13}$ Owing to the large penetration depth of (high energy) x-ray radiation, XAS and XRD can be applied in situ in the presence of gaseous or liquid reactants and solvents, using $\mathrm{x}$-ray transparent cells or windows that are able to withstand the high temperatures and pressures necessary to reach supercritical conditions. Among the commonly used supercritical fluids (water, $\mathrm{CO}_{2}$, and $\mathrm{NH}_{3}$ ), $\mathrm{SCW}$ presents the greatest challenge in terms of cell design due to its critical parameters $\left(\mathrm{p}_{\mathrm{c}}=22.1 \mathrm{MPa}, \mathrm{T}_{\mathrm{c}}=374^{\circ} \mathrm{C}\right)$ and corrosive nature.

In particular, a cell that enables measuring XAS and XRD under typical SCW conditions needs to fulfill the following five main requirements:

(1) mechanical strength to withstand operating pressures of up to $30 \mathrm{MPa}$,

(2) mechanical and thermal stability at temperatures up to $500^{\circ} \mathrm{C}$,

a) Author to whom correspondence should be addressed. Electronic mail: marian.dreher@psi.ch.
(3) resistance to corrosion under hydrothermal conditions,

(4) absence of crystallinity that could cause additional diffraction of the $x$-rays, and

(5) sufficient $x$-ray transmittance at the desired photon energy.

In the field of catalysis, it is furthermore desirable to investigate the catalyst during continuous operation while applying different reaction conditions such as flow rate, temperature, pressure, or variation of reactants. For catalysis under supercritical conditions, this requires a continuous flow reactor that fulfills all of the above requirements. In addition, the reactor must allow for the intimate contact of the supercritical fluid with the catalyst, which is usually achieved by operating the reactor in a "fixed-bed" mode. In the fixed-bed mode, the catalyst is placed and secured as a closely packed bed of fine particles within the tubular reactor.

Grunwaldt and Baiker reviewed the requirements that need to be taken into account when designing in situ XAS cells for catalytic reactions in supercritical fluids. ${ }^{14} \mathrm{~A}$ comprehensive review of the existing XAS cells for HT/HP catalytic fluid phase reactions, as well as suitable materials, was published by Kawai et al. ${ }^{15}$

Nearly all in situ XAS cells for HP/HT application found in literature are of the diamond-anvil type or batch reactors with $\mathrm{x}$-ray windows made from various materials such as Be, diamond, silica, or graphite. ${ }^{16-19}$ One of the most versatile and complex X-ray transparent batch reactors for in situ XAS and x-ray emission spectroscopy (XES) under SCW conditions has been designed by Testemale et al. and has been used extensively for geochemical applications. ${ }^{19-22}$ However, batch reactors do not allow the continuous flow operation, making it impossible to study catalysts under steady state or transient conditions. A promising in situ XAS cell for continuous flow operation was developed by Kawai et al. who studied hydro-desulfurisation reactions over $\mathrm{Ni}$ catalysts in hot oil at $450^{\circ} \mathrm{C}$ and $3 \mathrm{MPa}$ using cubic boron nitride as $\mathrm{x}$-ray windows. ${ }^{15}$ However, their reactor can only resist pressures up to $10 \mathrm{MPa}$, which is not sufficient to reach $\mathrm{SCW}$ 
conditions. Furthermore, boron nitride does not seem to be chemically stable in SCW. ${ }^{23-25}$

A general drawback of using reactors with $\mathrm{x}$-ray windows for catalytic reactions is the limitation of being able to probe the catalyst only in one spot. For studying catalytic reactions in detail, it can be necessary to probe the catalyst at different positions along the catalyst bed, which requires a reactor that is X-ray transparent along its entire length.

The continuous, supercritical water gasification (SCWG) of biomass or liquid waste is a promising approach for the production of sustainable energy. In this process, SCW acts as both, solvent and reactant, converting organic material to methane, hydrogen, and carbon dioxide. To maximize the conversion and the yield of methane gas, the reaction can be catalyzed by certain transition metals such as $\mathrm{Ru} .{ }^{4,28}$

In this paper, we introduce a novel type of x-ray transparent, continuous flow reactor, using polycrystalline aluminum nitride (AlN) as a reactor material, which is able to withstand SCW conditions. As an example, we present the first extended x-ray absorption fine structure (EXAFS) spectra of an active heterogeneous catalyst recorded under these conditions. Analysis of these spectra provides information on the local bonding environment (type and number of neighboring atoms, bond distances) of the $\mathrm{Ru}$ atoms of a carbon-supported ruthenium $(\mathrm{Ru} / \mathrm{C})$ catalyst during the continuous SCWG of ethanol.

\section{STRATEGY FOR CELL CONSTRUCTION}

\section{Choice of cell material}

Generally, many metals and metal alloys fulfill the conditions of mechanical strength, temperature stability, and resistance to corrosion, but have poor $\mathrm{x}$-ray transmittance, with the exception of beryllium, which should be avoided for safety reasons. This leaves ceramic materials as possible construction materials for an in situ cell. To keep the x-ray attenuation at a sufficiently low level, the ceramic material should be composed of light elements (e.g., up to Al). Furthermore, the mechanical strength needs to be very high in order to facilitate thin but strong reactor walls.

Boukis and co-workers ${ }^{23-25}$ conducted an extensive study on the corrosion resistance of several steel alloys and ceramics under hydrothermal conditions. From a spectroscopic point of view, out of this list of materials, boron carbide would be an ideal reactor material due to its outstanding x-ray transmittance and high mechanical strength. However, it is easily corroded under hydrothermal conditions. Of the ceramic materials composed of relatively light and thus X-ray transparent elements, tested in the mentioned studies, only sapphire and AlN proved to be sufficiently stable. Due to its high mechanical strength and corrosion resistance, sapphire is an excellent material for high pressure cells. ${ }^{26,27}$ However, its crystalline nature causes X-ray diffraction that interferes with the XAS signal and limits the analysis of the spectra to the position of the absorption edge (determination of oxidation state). ${ }^{27}$ This leaves AlN as the material of choice, presenting a mechanical strength similar to sapphire and exceptionally high heat conductivity. Furthermore, it transmits x-ray ra-

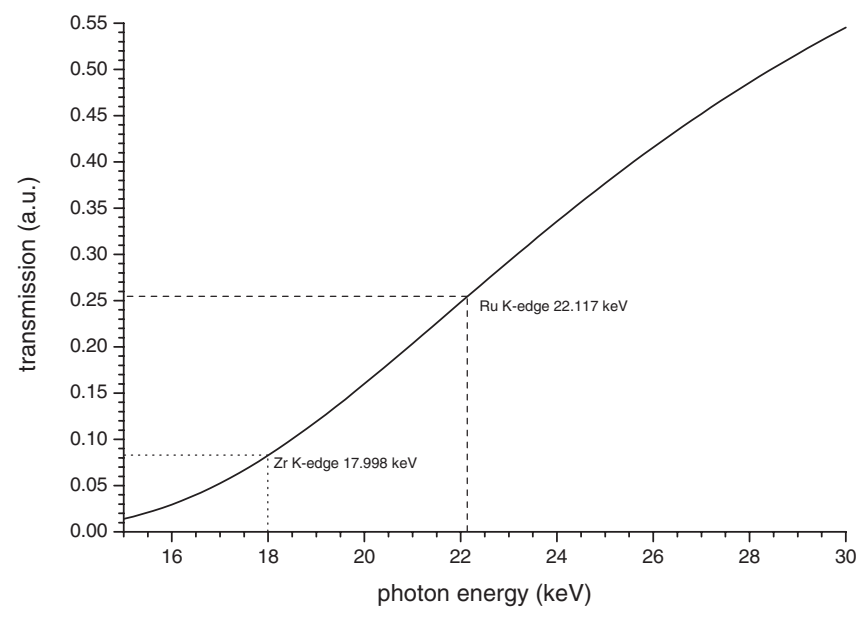

FIG. 1. X-ray transmission of an AlN tube with a wall thickness of $1.25 \mathrm{~mm}$.

diation without causing diffraction due to its polycrystalline nature.

For these reasons, tubular AlN was selected as the material of choice for reactor construction. A tubular design, where the entire reactor is made of an x-ray transmitting material, has a clear advantage over window-type reactors; it allows for spatial resolution along its entire length.

It needs to be noted, though, that the x-ray attenuation of AlN is still relatively high compared to materials like beryllium or boron carbide. The energy dependence of the x-ray transmittance of a tubular AIN reactor with a wall thickness of $1.25 \mathrm{~mm}$, as developed in this study, is shown in Figure $1 .{ }^{29}$ At a photon energy of $18.5 \mathrm{keV}$, only $10 \%$ of the photons are transmitted through the reactor walls and transmission quickly decreases to zero at lower energies. Therefore, the proposed reactor design (inner diameter of $3.5 \mathrm{~mm}$, outer diameter of $6.0 \mathrm{~mm}$ ) limits fast EXAFS spectroscopy (with acquisition times of a few minutes) to absorbers heavier than $\mathrm{Zr}$. Measurements at lower energies are possible, but require long acquisition times to achieve good signal statistics.

However, by decreasing the inner diameter of the AlN tube, the wall thickness necessary to withstand the pressure during SCW conditions also decreases, thus enabling thinner walls and measurements at lower photon energies. It needs to be kept in mind, though, that the amount of sample in the x-ray beam decreases with decreasing inner diameter. Hence, signal intensity is lowered, which might be a problem when investigating very dispersed absorbers such as supported catalysts with low metal loading. In contrast, for samples with a sufficient concentration of x-ray absorbing atoms, reducing inner diameter and wall thickness would be a viable option to perform XAS at low-photon energies.

\section{Construction of the continuous flow, in situ reactor}

Figure 2 shows a 3D model of the complete reactor as well as an enlargement of the catalytic zone.

As the centerpiece of the $\mathrm{x}$-ray transparent cell, an AlN tube with dimensions $3.5 \times 6.0 \times 200 \mathrm{~mm}$ (CeramTec GmbH, 


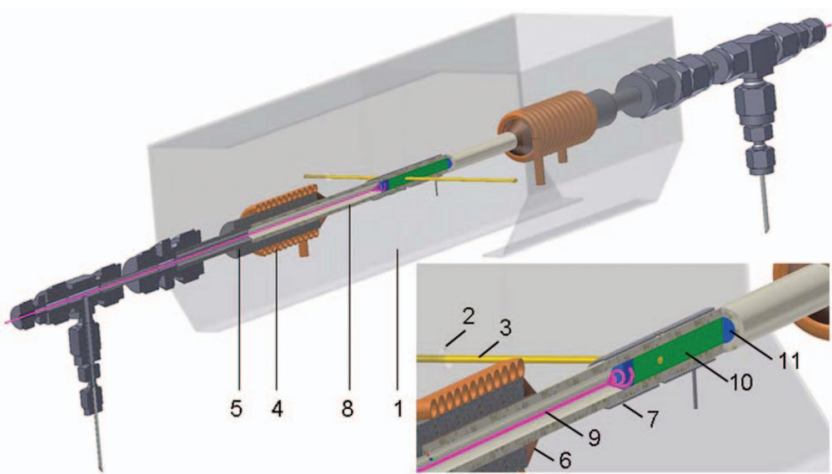

FIG. 2. 3D model of the in situ reactor. 1: safety shield, 2: aperture for X-ray beam, 3: x-ray beam, 4: coil of copper tubing, 5: stainless steel casing, 6: epoxide glue, 7: coil of heating wire, 8: AlN tube, 9: thermocouple, 10: catalyst bed, and 11: stainless steel frit.

Germany) was used. In order to connect the AlN tube to the high pressure system employed in this study, its ends were glued into stainless steel casings, using high performance epoxide glue, which is stable up to $300{ }^{\circ} \mathrm{C}$ (Kager Industrieprodukte, Germany). To maximize the contact area of the glue, both the casings and the AlN tube were sandblasted prior to caulking. The ends of the steel casings were machined to $6 \mathrm{~mm}$ in diameter to allow for connection to Swagelok ${ }^{\circledR}$ fittings.

Due to the high heat conductivity of AIN and the relatively short reactor tube, the steel casings needed to be water cooled in order to guarantee the mechanical stability of the epoxide glue and to prevent overheating. This was achieved by coils of copper tubing, wrapped around the steel casings. Heat conducting paste was used to maximize the cooling efficiency.

A flexible heating was realized with a coil of resistive wire, tightly wrapped around the center of the reactor. In this case, an iron-nickel alloy (Monel) was used due to its resistance to oxidation at high temperatures. In order to allow the $\mathrm{x}$-ray beam to pass through the heating unhindered, the twines in the center of the heating coil were pulled apart to a sufficient extent. A remotely controllable ac/dc converter was used to power the heating.

For operation at the SuperXAS beamline, the in situ reactor was supported on an aluminum rack and encased in a safety shield made of $1 \mathrm{~mm}$ stainless steel. Small openings in the safety shield at the level of the reactor tube allowed the $\mathrm{X}$-ray beam to pass through unhindered.

\section{High pressure liquid feed system}

Figure 3 shows a systematic sketch of the high pressure liquid feed system. The entire piping was constructed from stainless steel capillaries with Swagelok connections. Capillary diameters were kept as small as possible to minimize the inner volume of the setup. The 1/16 in. capillaries were installed wherever feasible, greatly reducing the time lag between the switch valve and the reactor. Furthermore, it improves the precision of liquid effluent analysis by eliminating dead space inside the piping. When a liquid-gas mixture is present anywhere in the system, as in the present study, particular attention needs to be paid to the orientation of certain parts such as valves and sensors to avoid the accumulation of compressed gas. ${ }^{30}$

The key components of the continuous flow setup are two syringe pumps (Teledyne-ISCO, Model 260D) that allow pumping liquids and viscous slurries with a flow rate precision of $5 \mu \mathrm{l} / \mathrm{min}$ at pressures up to $60 \mathrm{MPa}$. Furthermore, the pressure sensor of the pumps records the system pressure upstream of the reactor. The two pumps are linked to the feed capillary by a six-port high-performance liquid chromatography (HPLC) switch valve allowing for remote switching between different feeds. The switch valve is connected directly to the reactor after which the effluent passes through a heat exchanger and a particle filter (pore size $5 \mu \mathrm{m}$ ). At this point, a T-junction connects to a safety valve and a pressure sensor that records the system pressure downstream of the reactor. The final component of the high pressure setup is a high precision back pressure regulator, optimized for low flow rates (TESCOM, Model 26-1700), where the effluent stream is allowed to expand directly from system to ambient pressure. Gaseous reaction products are then segregated from the liquid phase in a phase separator. Here, liquid samples can be taken for further analysis. The gas phase passes through a bed of calcium chloride to remove moisture and is analyzed online via a mass spectrometer or gas chromatograph.

\section{EXAFS measurements}

EXAFS measurements under SCW conditions were carried out in transmission mode at the $\mathrm{Ru} \mathrm{K}$-edge at the $\mathrm{Su}$ perXAS beamline of the Swiss Light Source (SLS), Villigen, Switzerland. The SLS is a third generation light source with a storage ring energy of $2.4 \mathrm{GeV}$, a current of $400 \mathrm{~mA}$, and top-up injection.

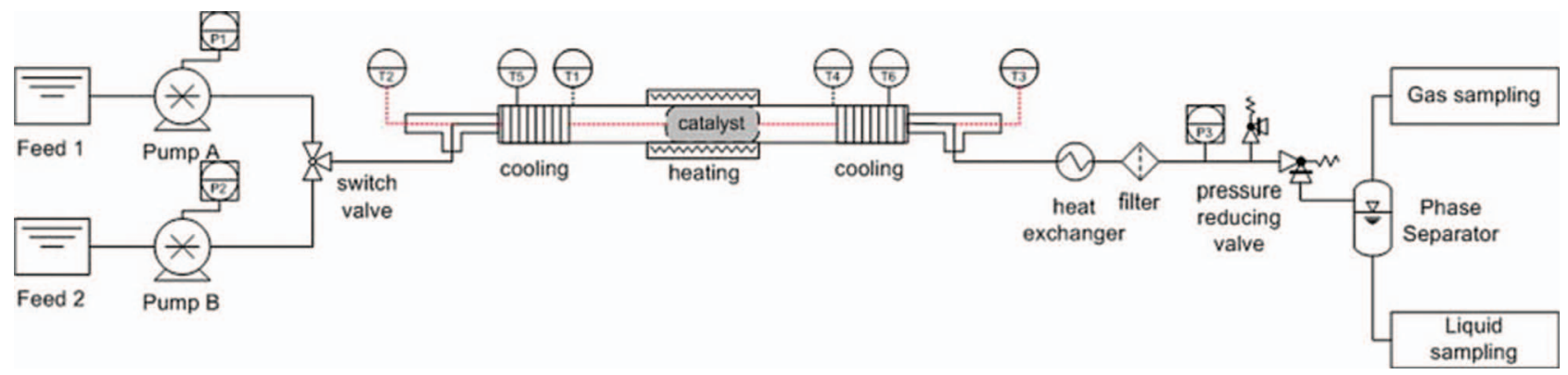

FIG. 3. Sketch of the entire setup. Tx designates installed thermocouples, Px the installed pressure sensors. 
The beam was monochromatized with a Si (311) double crystal monochromator and was focused on the sample to a size of $3000 \times 500 \mu \mathrm{m}$. The monochromator was operated in "on-the-fly" mode, which allowed the collection of one full EXAFS spectrum in $180 \mathrm{~s}$. The incident and transmitted intensities were monitored by ionization chambers filled with Ar.

\section{RESULTS AND DISCUSSION}

\section{Operation of the in situ cell}

Before operation at the beamline, the in situ cell was pressure tested to $30 \mathrm{MPa}$ at room temperature for $3 \mathrm{~h}$ in our high pressure laboratory. The in situ reactor was then used in a study of catalytic biomass gasification and operated almost continuously at $24 \mathrm{MPa}$ and $400{ }^{\circ} \mathrm{C}$ for 5 days. During that time, no material failure occurred, nor could any degradation of the reactor material be observed. The electrical power of $120 \mathrm{~W}$ was sufficient to heat the catalytic zone of the reactor to $400{ }^{\circ} \mathrm{C}$ at a rate of $4 \mathrm{~K} / \mathrm{s}$ while a solution of $7.5 \mathrm{wt} . \% \mathrm{EtOH}$ in water was fed at a flow rate of $0.5 \mathrm{ml} / \mathrm{min}$.

As AlN has a high temperature shock stability, experiments involving fast heating-cooling cycles are not expected to present a problem.

Due to the high heat conductivity of AlN, overheating and mechanical failure of the epoxide glue were a concern. However, the water cooling was efficient enough to keep the temperature of the steel casings well below $100^{\circ} \mathrm{C}$ (thermocouples T5 and T6 in Figure 3). Temperatures measured at the transition point between the bare and encased parts of the AlN tube (thermocouples T1 and T4 in Figure 3) never exceeded $180^{\circ} \mathrm{C}$.

\section{Considerations on safety}

The results of Boukis et al. show that the surface of AlN is slowly attacked under hydrothermal conditions with a mass change of $4.8 \mathrm{mg} / \mathrm{cm}^{2}$ after $80 \mathrm{~h}^{23}$ However, a very corrosive supercritical medium, containing hydrogen peroxide and hydrochloric acid, was used in their study. The results further suggest that there is no single ceramic material, which is generally stable under hydrothermal conditions. The composition of the supercritical medium (e.g., acidic vs. basic, ionic species) has a significant influence on the corrosion rate and needs to be taken into account when evaluating the reactor lifetime. Generally, long-term operation using strongly corrosive fluids (acidic and/or oxidative) should be avoided while strongly caustic fluids should not be used altogether, as they are known to hydrolyse AlN. ${ }^{31}$ We suggest to inspect regularly the inside of the in situ reactor and to install a fresh AIN tube after $80 \mathrm{~h}$ of online operation.

$$
p=\frac{20 w \frac{K}{s}}{D-w} .
$$

Equation (1): Calculation of the pressure stability of a ceramic tube. p: Pressure in MPa, w: wall thickness, K: tensile strength of the ceramic material in MPa, s: safety factor $(\geq 1)$, D: outer diameter. ${ }^{32}$
The reactor should be enclosed in a safety shield at all times during operation, since the structural failure of the AlN tube will lead to a steam explosion and the generation of ceramic shrapnel. Based on the mechanic properties of sintered AlN and Eq. (1), the in situ reactor presented here has a calculated rupture pressure of $79 \mathrm{MPa}$, applying a safety factor of $2 .{ }^{31,32}$ The reactor was pressure-tested at $30 \mathrm{MPa}$ and $450^{\circ} \mathrm{C}$ for $2 \mathrm{~h}$ during which no leakage or structural failure occurred.

\section{In situ EXAFS of a carbon supported Ru catalyst during SCWG of ethanol}

Ruthenium is a potent catalyst for the reforming of organics such as biomass to obtain a methane-rich product gas (synthetic natural gas, SNG). In particular, carbon supported $\mathrm{Ru}$ nanoparticles were shown to be highly active in the catalytic SCWG of model biomass such as glycerol, as well as real biomass. ${ }^{5,19}$ In this process, supercritical water serves as solvent and reactant at the same time, dissolving and breaking down large bio-molecules to form smaller organic moieties that are readily gasified by the Ru catalyst. After cooling and phase separation, a product gas with high methane content is obtained.

In the presented study, ethanol was chosen as a very simple model for real biomass and gasified in SCW. The in situ reactor was loaded with $150 \mathrm{mg}$ of $2 \% \mathrm{Ru} / \mathrm{C}$ (BASF), fixed between two stainless steel frits (pore size $5 \mu \mathrm{m}$ ). At room temperature, the setup was brought to an operating pressure of $24 \mathrm{MPa}$ by pumping DI water at a flow rate of $0.5 \mathrm{ml} / \mathrm{min}$. The feed was then switched to $7.5 \mathrm{wt}$. \% ethanol in water while keeping the flow rate constant. Under these conditions, the catalyst was present in its fully oxidized form $\mathrm{RuO}_{2}$, as confirmed by EXAFS. Stepwise heating up to supercritical conditions showed that reduction of the $\mathrm{RuO}_{2}$ particles to $\mathrm{Ru}^{0}$ started at $130^{\circ} \mathrm{C}$ and was complete at $200^{\circ} \mathrm{C}$ (Figure 4). The catalyst then remained in its reduced form,

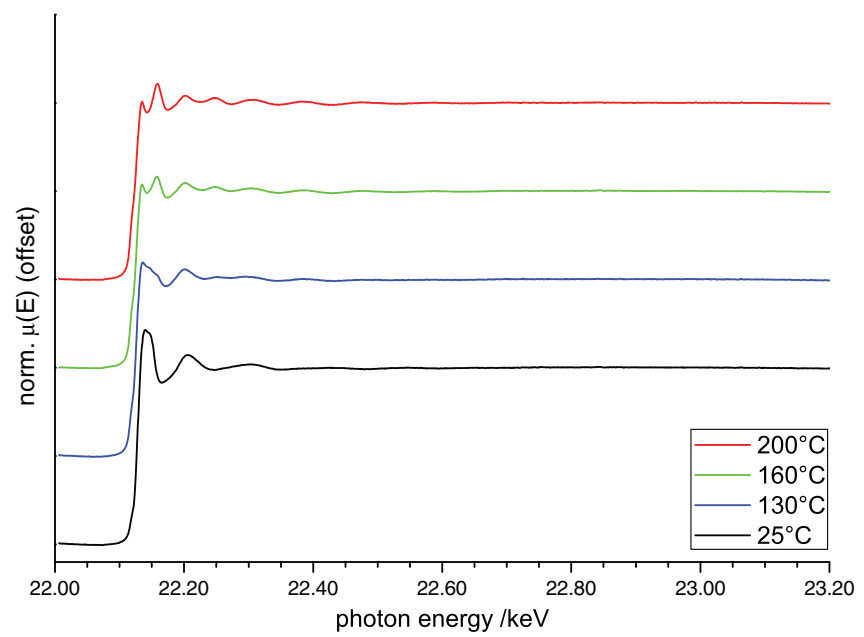

FIG. 4. Normalized Ru K-edge EXAFS spectra of fresh $2 \% \mathrm{Ru} / \mathrm{C}$ in a continuous flow of 7.5 wt. \% ethanol in $\mathrm{H}_{2} \mathrm{O}$ at various temperatures. All spectra were recorded at $24 \mathrm{MPa}$ with an acquisition time of $180 \mathrm{~s}$. 


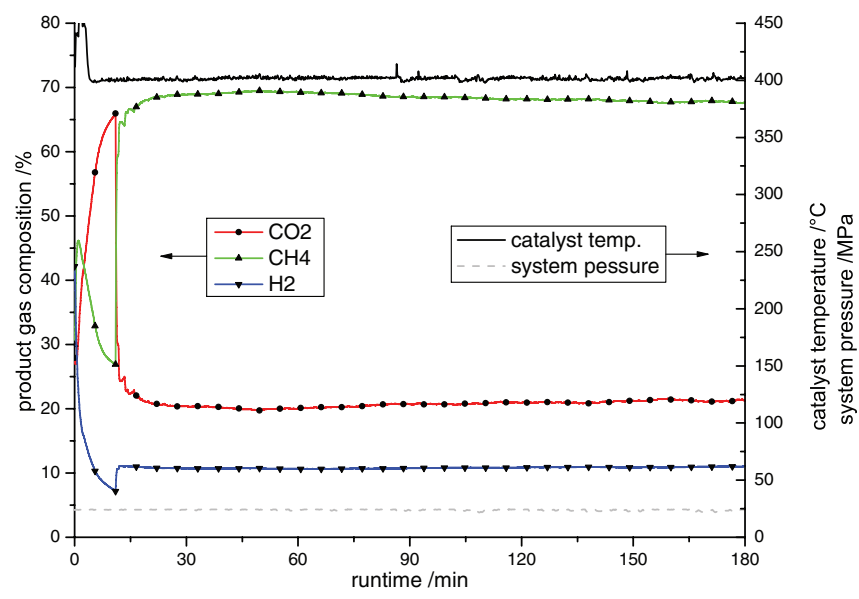

FIG. 5. Time-averaged product gas composition, calculated from MS gas analysis, of the SCWG of ethanol over $2 \% \mathrm{Ru} / \mathrm{C}$ at $400^{\circ} \mathrm{C}$ and $24 \mathrm{MPa}$.

which represents the active phase during SCWG of ethanol at $400{ }^{\circ} \mathrm{C}$, confirming previous results. ${ }^{18}$ Typical reaction conditions and product gas composition, obtained from online mass spectrometric gas analysis (Omnistar GSD 301 02, Pfeiffer, Germany), are depicted in Figure 5. To the best of our knowledge, these are the first full EXAFS spectra recorded under SCW and continuous flow conditions.

At supercritical conditions $\left(400^{\circ} \mathrm{C}, 24 \mathrm{MPa}\right)$, damping of the EXAFS signal due to the high temperature is visible (Figure 6). However, data quality remained high up to $\mathrm{k}=12 \AA^{-1}$, allowing for the analysis of Ru particle structure and size during hydrothermal ethanol gasification, which will be reported elsewhere.

\section{CONCLUSION}

A novel, continuous flow reactor was constructed that is able to withstand the demanding conditions of supercritical water ( $\mathrm{p}>22.1 \mathrm{MPa}, \mathrm{T}>374^{\circ} \mathrm{C}$ ) and is resistant to chemical attack by the supercritical medium. This was achieved by

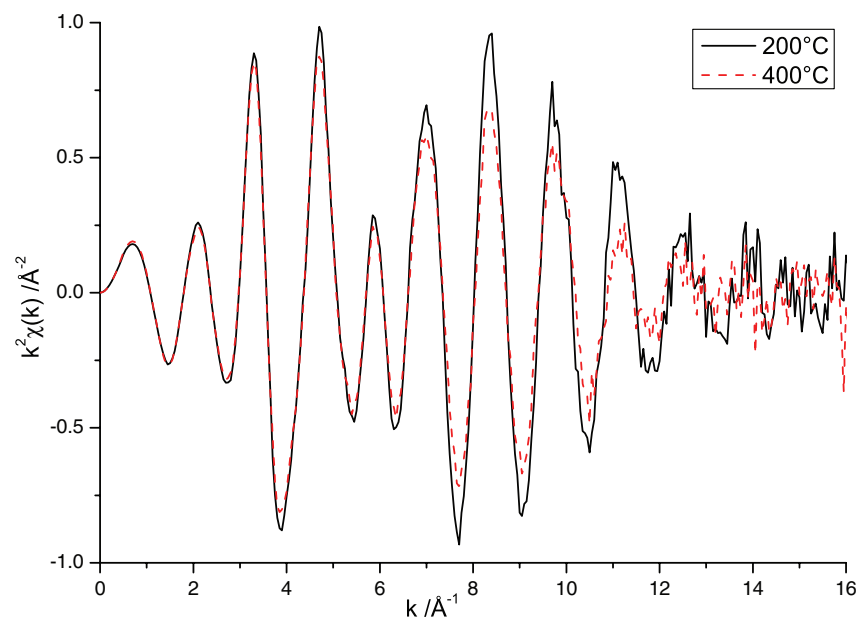

FIG. 6. EXAFS spectra of the active $2 \% \mathrm{Ru} / \mathrm{C}$ catalyst in sub- $\left(200^{\circ} \mathrm{C}\right)$ and supercritical $\left(400^{\circ} \mathrm{C}\right)$ water at $24 \mathrm{MPa}$ (acquisition time: $\left.180 \mathrm{~s}\right)$. Damping of the EXAFS signal is well visible at $400^{\circ} \mathrm{C}$. employing AlN as the reactor material, which is an inexpensive, nontoxic, and highly stable ceramic.

For the first time, the in situ EXAFS spectra of a supported metal catalyst in supercritical water were recorded, allowing for the analysis of the catalyst's local structure and electronic state under these reaction conditions.

The presented continuous flow reactor may be used for investigating a plethora of catalytic as well as non-catalytic chemical reactions in gaseous, liquid, and supercritical media. Its application is not only limited to the field of XAS, but also offers a viable option for in situ XRD under high $\mathrm{T}$ and $\mathrm{p}$ conditions.

\section{ACKNOWLEDGMENTS}

This project was funded by the Swiss National Science Foundation (NSF(CH)) (Grant No. 200021_130615). The authors thank A. Wokaun and an anonymous reviewer for valuable discussions, C. F. J. König, E. M. C. Alayon, and T. Wölfl for their support during beamtime as well as M. Hottiger and P. Hottinger for technical assistance.

${ }^{1}$ B. Simoneit, Geochim. Cosmochim. Acta 57, 3231 (1993).

${ }^{2}$ R. Fournier, Econ. Geol. 94, 1193 (1999).

${ }^{3}$ Z. Ronghua, Z. Xuetong, and H. Shumin, Tectonophysics 502, 276 (2011).

${ }^{4}$ D. Elliott, Biofuel. Bioprod. Bior. 2, 254 (2008)

${ }^{5}$ M. Waldner and F. Vogel, Ind. Eng. Chem. Res. 44, 4543 (2005).

${ }^{6}$ Z. Fang, T. Minowa, R. Smith, T. Ogi, and J. Kozinski, Ind. Eng. Chem. Res. 43, 2454 (2004).

${ }^{7}$ A. Onda, T. Ochi, and K. Yanagisawa, Green Chem. 10, 1033 (2008).

${ }^{8}$ D. Dodds and R. Gross, Science 318, 1250 (2007).

${ }^{9}$ X. Tong, Y. Ma, and Y. Li, Appl. Catal., A 385, 1 (2010).

${ }^{10}$ A. Demirbas, Energy Convers. Manage. 42, 279 (2001).

${ }^{11}$ F. Cherubini, Energy Convers. Manage. 51, 1412 (2010).

${ }^{12}$ D. C. Koningsberger and R. Prins, in x-Ray Absorption: Principles, Applications, Techniques of EXAFS, SEXAFS and XANES (Wiley, New York, 1988).

${ }^{13}$ H. Jensen, M. Bremholm, R. P. Nielsen, K. D. Joensen, J. S. Pedersen, H. Birkedal, Y.-S. Chen, J. Almer, E. G. Søgaard, S. Brummerstedt Iversen, and B. Brummerstedt Iversen, Angew. Chem., Int. Ed. 46, 1113 (2007)

${ }^{14}$ J.-D. Grunwaldt and A. Baiker, "X-ray absorption fine structure-XAFS13," AIP Conf. Proc. 882, 577 (2007).

${ }^{15}$ T. Kawai, W.-J. Chun, K. Asakura, Y. Koike, M. Nomura, K. Bando, S. Oyama, and H. Sumiya, Rev. Sci. Instrum. 79, 014101 (2008).

${ }^{16}$ R. Mayanovic, H. Yan, A. Anderson, P. Meredith, and W. Bassett, J. Phys. Chem. C 116, 2218 (2012).

${ }^{17}$ H. Yan, R. Mayanovic, A. Anderson, and P. Meredith, Nucl. Instrum. Methods Phys. Res. A 649, 207 (2011).

${ }^{18}$ T. M. Seward, C. M. B. Henderson, J. M. Charnock, and B. R. Dobson, Geochim. Cosmochim. Acta 60, 2273 (1996).

${ }^{19}$ D. Testemale, R. Argoud, O. Geaymond, and J. L. Hazemann, Rev. Sci. Instrum. 76, 043905 (2005).

${ }^{20}$ V. Ranieri, J. Haines, O. Cambon, C. Levelut, R. Le Parc, M. Cambon, and J. L. Hazemann, Inorg. Chem. 51, 414 (2012).

${ }^{21}$ D. Testemale, J. Brugger, W. H. Liu, B. Etschmann, and J. L. Hazemann, Chem. Geol. 264, 295 (2009).

${ }^{22}$ D. Testemale, G. S. Pokrovski, and J. L. Hazemann, Eur. J. Mineral. 23, 379 (2011).

${ }^{23}$ N. Boukis, N. Claussen, K. Ebert, R. Janssen, and M. Schacht, J. Eur. Ceram. Soc. 17, 71 (1997).

${ }^{24}$ P. Kritzer, N. Boukis, and E. Dinjus, Corrosion 56, 1093 (2000).

${ }^{25}$ M. Schacht, N. Boukis, and E. Dinjus, J. Mater. Sci. 35, 6251 (2000).

${ }^{26} \mathrm{M}$. Bremholm, H. Jensen, S. Brummerstedt Iversen, and B. Brummerstedt Iversen, J. Supercrit. Fluids 44, 385 (2008).

${ }^{27}$ S. Rabe, M. Nachtegaal, T. Ulrich, and F. Vogel, Angew. Chem., Int. Ed. 49, 6434 (2010). 
${ }^{28}$ P. Azadi and R. Farnood, Int. J. Hydrogen Energy 36, 9529 (2011).

${ }^{29}$ B. Henke, E. Gullikson, and J. Davis, At. Data Nucl. Data Tables 54, 181 (1993).

${ }^{30}$ S. Rabe, M. Nachtegaal, T. Ulrich, and F. Vogel, Angew. Chem. Int. Ed. 51(11), 2533 (2012).
${ }^{31}$ B. H. Mussler, Am. Ceram. Soc. Bull. 79(6), 45 (2000), see http://www. anceram.com/pdf/aln_artikel_bull.pdf for more information.

${ }^{32} \mathrm{See} \quad$ http://www.iacs.org.uk/document/public/publications/unified_ requirements/pdf/ur_p_pdf157.pdf for more information about International Association of Classification Societies, Requirements Concerning Pipes and Pressure Vessels. 